\title{
Prevalence and Determinants of Anemia in Pregnancy, Sana'a, Yemen
}

\author{
Yousef M. Alflah ${ }^{1}$, Iman H. Wahdan ${ }^{2}$, Ali A. Hasab ${ }^{3}$, Dalia I. Tayel ${ }^{4}$ \\ ${ }^{1}$ Public Health Specialist, Al Kuwait University Hospital, Sana'a University, Yemen \\ ${ }^{2,3}$ Department of Epidemiology, High Institute of Public Health, Alexandria University, Egypt \\ ${ }^{4}$ Department of Nutrition, High Institute of Public Health, Alexandria University, Egypt
}

\begin{tabular}{l} 
Article Info \\
\hline Article history: \\
Received May 28, 2017 \\
Revised Jul 26, 2017 \\
Accepted Aug 11, 2017 \\
\hline Keyword: \\
Anemia \\
Determinants of anemia \\
Pregnant women \\
Prevalence
\end{tabular}

\begin{abstract}
Anemia is a global public health problem in both developing and developed countries, especially among pregnant women. The aim of the study was to estimate the prevalence of anemia among pregnant women in Sana'a governorate, Yemen, and to identify the determinants contributing to it, and to assess knowledge regarding it. The study was conducted using a crosssectional approach. It included 360 pregnant women attending the maternity clinics of maternity hospitals. A predesigned structured interviewing questionnaire was used to collect data from the pregnant women. Laboratory investigations were done. The prevalence of anemia was found to be $40.3 \%$, and was higher among females aged 35 to less than 45 years, those with poor income and poor nutritional level. The risk of anemia increased with the gestational age, gravidity, decreased birth spacing, drinking tea and coffee after meals, decreased intake of proteins and low level of knowledge and income. The binary logistic regression model indicated a significant impact of the education and occupation on the level of knowledge of pregnant women. Anemia was found out to be a severe public health problem among pregnant women in Yemen. Identified risk factors should be considered for its prevention and control.
\end{abstract}

Copyright () 2017 Institute of Advanced Engineering and Science. All rights reserved.

\section{Corresponding Author:}

Yousef Mohammed Ali Al-Flah, Public Health Specialist, Alkuwait University Hospital, Sana'a University, Sana'a, Yemen. Email: alflah2014@gmail.com

\section{INTRODUCTION}

Anemia is a global public health problem affecting both developing and developed countries with major consequences for human health as well as social and economic development. It occurs in all stages of life but it is more prevalent in pregnant women and children [1]. The World Health Organization (WHO) considered anemia to be one of the ten most important factors contributing to the global burden of diseases [2]. The Centers for Disease Control and Prevention (CDC), estimated the worldwide prevalence of anemia among pregnant women to be $52 \%$ in 2007 . The majority of these women were living in developing countries [3]. Globally, according to the WHO, in 2014, the prevalence of anemia among pregnant women aged 15-49 years fell by $12 \%$ between 1995 and 2011 from $43 \%$ to $38 \%$ [4].

Anemia in pregnancy is defined as a decrease in the concentration of circulating red blood cells or in the hemoglobin concentration (hemoglobin levels of below $11 \mathrm{~g} / \mathrm{dl}$ ) and a concomitant impaired capacity to transport oxygen [2]. Anemia is a multi-factorial disorder. At least half of the global burden of anemia in pregnancy is due to iron deficiency. Other contributing factors include nutritional deficiencies of folate, vitamin B12 and vitamin A, chronic inflammation, parasitic infections and inherited disorders [5]. Anemia in 
pregnancy is also affected by socioeconomic conditions, lifestyles and health-seeking behaviors across different cultures [2].

Studies have shown that anemia in pregnancy has adverse consequences that may not only affect the pregnant but also affects the neonate and infant [6]. During pregnancy, anemia is associated with multiple adverse outcomes for both mother and infant, including an increased risk of hemorrhage, sepsis, maternal mortality, perinatal mortality, low birth weight [7] and reduced work capacity [8]. Forty percent of all perinatal deaths are linked to anemia [7]. There is usually a 2 to 3 fold increase in perinatal mortality rate when maternal hemoglobin levels fall below $8.0 \mathrm{~g} / \mathrm{d} 1$ and 8-10 folds increase when maternal hemoglobin levels fall below $5.0 \mathrm{~g} / \mathrm{dl}$ [9].

The management of anemia in a pregnant woman depends on the duration of pregnancy, severity of the anemia and complications [10]. The WHO reported that a combined treatment with iron and vitamin A could have a greater impact on anemia treatment especially during the second trimester of pregnancy [11]. Interventions to control anemia in pregnancy include iron supplementation and iron fortification, dietary modification, nutritional and health education, control of parasitic infections, and improvement of sanitation [5],[12],[13].

In Yemen, anemia is one of the serious health problems among pregnant women. In 2011, the World Bank estimated the prevalence of anemia in Yemen to be $36 \%$ among pregnant women [14]. Therefore, the assessment of the extent of the problem and the factors responsible for it is needed. The present study aimed to estimate the prevalence of anemia among pregnant women in Sana'a governorate, Yemen, to identify the determinants contributing to it, and to assess knowledge regarding it.

\section{METHOD}

The study was carried out among pregnant women attending the outpatient clinics of four governmental hospitals in Sana'a governorate (Alsba'aen Hospital, Alkuwait University Hospital, Althawra General Hospital and Aljumhory Hospital) using a cross sectional design. The sample size was calculated using Stats Direct 3.0.135, 2015. Based on prevalence of anemia of $36 \%$ among pregnant women, ${ }^{(14)}$ the minimum required sample size was calculated to be 360 pregnant women at $95 \%$ confidence interval, and $5 \%$ acceptable absolute deviation of the sample from the population rate.

A pre-designed structured interviewing questionnaire was prepared by the researchers to collect data from pregnant women about their sociodemographic characteristics including age, educational level, occupation, income level, and residence. Obstetric and gynecological history was obtained (including trimester of pregnancy, gravidity, previous births, and history of abortion). Medical history (chronic and current diseases), dietary habits (use of vitamin and mineral supplements, consumption of enhancers and inhibitors of iron absorption were obtained. The questionnaire also included knowledge about signs, symptoms, complications and risk factors of anemia, iron rich foods and enhancers and inhibitors of iron absorption. Laboratory investigations were done to assess the level of hemoglobin, hematocrit (Hct), packed cell volume (PCV), mean corpuscular hemoglobin concentration (MCHC) and volume of the red blood cell.

$$
\mathrm{MCHC}=\mathrm{Hb}(\mathrm{g} / \mathrm{dl}) / \mathrm{Hct}(\%) \times 100
$$

The collected data were revised, coded, and analyzed using the statistical package for social sciences (SPSS version 21). Graphical presentations were done for visualization using Microsoft Excel. Mean (X) with standard deviation (SD) were calculated to describe normally distributed scale data. Count and percentage were used describing and summarizing qualitative data. A special scoring system was prepared for assessment of dietary intake and knowledge. Chi-square $\left(\mathrm{X}^{2}\right)$ was used for analysis of some categorical data. Odds ratio was used to assess the risk of a particular outcome (or disease) if a certain factor (or exposure) is present. Logistic regression was used to predict a dependent variable based on continuous and/or categorical independents and to determine the effect size of the independent variables on the dependent; to rank the relative importance of independents and to understand the impact of covariate control variables. The Receiver Operating Characteristic (ROC) curve analysis was also used to study the diagnostic performance of HB for diagnosis of anemia among pregnant females and discriminate anemic cases from normal cases.

The researcher sought the approval of the Ethics Committee of the High Institute of Public Health for conducting the research and complied with the international guidelines for research ethics. An informed written consent was taken from the study participants after explanation of the purpose and benefits of the research. Anonymity and confidentiality were assured and maintained. There was no conflict of interest. 


\section{RESULTS}

The total number of pregnant women included in the study was 360 women. Their Sociodemographic characteristics are shown in Table 1. The age of the pregnant women ranged between 15 and 45 years. The mean age was 26.55 years \pm 5.713 SD. Most pregnant women $(89.4 \%)$ were from urban areas. More than three quarters of pregnant women $(76.4 \%)$ were housewives. Only $19.6 \%$ were students. $2.8 \%$ were employees and free workers and professionals constituted $0.6 \%$. Only $12.2 \%$ of pregnant women were illiterate. Those with primary education constituted $26.4 \%$. Nearly half $(48.6 \%)$ of the study population had secondary education, while $12.8 \%$ had university and post graduate education. Pregnant women who had enough income constituted $70.5 \%$, compared to $21.7 \%$ who did not have enough income and borrow. Only $7.8 \%$ had enough income and saved.

Table 1. Distribution of Pregnant Women According to Socio-demographic Characteristics

\begin{tabular}{lcc}
\hline Sociodemographic data $(\mathrm{n}=360)$ & No & $\%$ \\
\hline Age (years) & & \\
$15-$ & 148 & 41.2 \\
$25-$ & 169 & 46.9 \\
$35-45$ & 43 & 11.9 \\
Mean $\pm \mathrm{SD}=26.55 \pm 5.7$ years & & \\
Residence & 322 & 89.4 \\
$\quad$ Urban & 38 & 10.6 \\
$\quad$ Rural & & \\
Occupation & 275 & 76.4 \\
Housewives & 71 & 19.6 \\
Students & 10 & 2.8 \\
Employees & 2 & 0.6 \\
Free workers & 2 & 0.6 \\
$\quad$ Professionals & & \\
Educational level & 44 & 12.2 \\
Illiterate & 95 & 26.4 \\
Primary & 175 & 48.6 \\
Secondary & 46 & 12.8 \\
University and post graduate & & \\
Income & 28 & 7.8 \\
Enough and save & 254 & 70.5 \\
Enough & 78 & 21.7 \\
$\quad$ Not enough and borrow & & \\
\hline
\end{tabular}

The study revealed that the overall prevalence of anemia among the study population was $40.3 \%$, where $16.6 \%$ of anemic pregnant women had mild anemia, $23.1 \%$ had moderate anemia, and only $0.6 \%$ of them had severe anemia as shown in Figure 1. The mean Hb level among pregnant women was $11.4 \pm 1.8$ $\mathrm{g} / \mathrm{dl}$. It ranged between 4 and $17 \mathrm{~g} / \mathrm{dl}$.

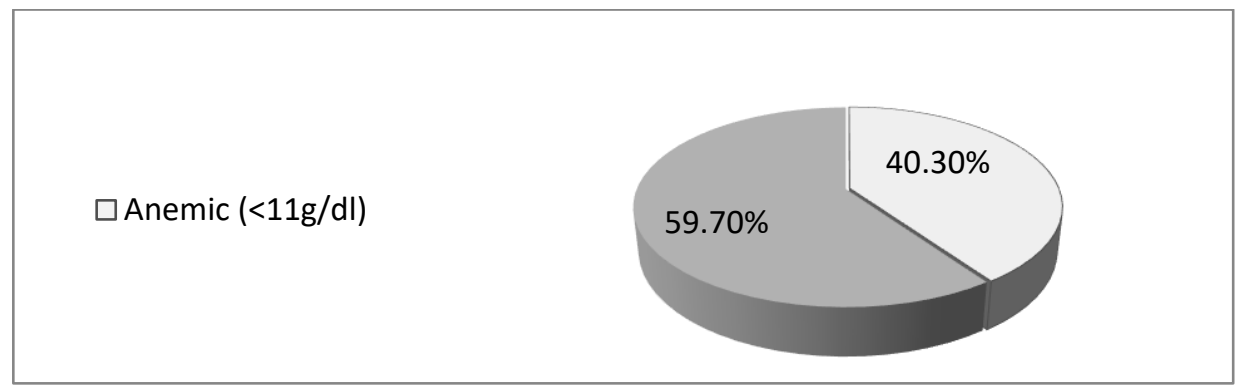

Figure 1. Distribution of pregnant women by their hemoglobin level

Table 2 shows that the highest prevalence of anemia (48.8\%) was found among pregnant women aged 35- 45 years, followed by those aged 25 to less than 35 years (42.6\%). The difference between various age groups in relation to anemia was not significant $(p=0.190)$. The prevalence of anemia increased with the decrease in the level of income. The highest prevalence of anemia (49.9\%) was among pregnant women who had poor income. The relation between income and anemia was statistically significant $(p=0.036)$. The prevalence of anemia increased with the increase in gestational age. It was $29.2 \%$ among women in the first 
trimester and increased to $42.5 \%$ and $48.7 \%$ among those in second and third trimester respectively. This increase is statistically significant $\left(\mathrm{x}^{2}=9.356, \mathrm{p}=0.009\right)$.

Table 2. Comparison Between Anemic and Non-anemic Pregnant Women in Relation to Sociodemographic Characteristics and Gynecological History

\begin{tabular}{|c|c|c|c|c|c|c|}
\hline \multirow{2}{*}{$\begin{array}{l}\text { Sociodemographic characteristics and } \\
\text { gynecologic history }\end{array}$} & \multicolumn{2}{|c|}{ Anemic $n=145$} & \multicolumn{2}{|c|}{ Not anemic $n=215$} & \multirow{2}{*}{$X^{2}$} & \multirow[b]{2}{*}{ p- value } \\
\hline & No & $\%$ & No & $\%$ & & \\
\hline \multicolumn{7}{|l|}{ Age (years) } \\
\hline $15-$ & 52 & $35.1 \%$ & 96 & $64.9 \%$ & \multirow{3}{*}{3.317} & \multirow{3}{*}{0.190} \\
\hline $25-$ & 72 & $42.6 \%$ & 97 & $57.4 \%$ & & \\
\hline $35-45$ & 21 & $48.8 \%$ & 22 & $51.2 \%$ & & \\
\hline \multicolumn{7}{|l|}{ Income level } \\
\hline Enough and save & 5 & $17.9 \%$ & 23 & $82.1 \%$ & \multirow{3}{*}{6.654} & \multirow{3}{*}{0.036} \\
\hline Enough & 105 & $41.3 \%$ & 149 & $58.7 \%$ & & \\
\hline Not enough and borrow & 35 & $44.9 \%$ & 43 & $55.1 \%$ & & \\
\hline \multicolumn{7}{|l|}{ Period of the current pregnancy } \\
\hline First trimester & 33 & $29.2 \%$ & 80 & $70.8 \%$ & \multirow{3}{*}{9.356} & \multirow{3}{*}{0.009} \\
\hline Second trimester & 57 & $42.5 \%$ & 77 & $57.5 \%$ & & \\
\hline Third trimester & 55 & $48.7 \%$ & 58 & $51.3 \%$ & & \\
\hline \multicolumn{7}{|l|}{ Current pregnancy order } \\
\hline $1-$ & 62 & $32.8 \%$ & 127 & $67.2 \%$ & \multirow{3}{*}{8.573} & \multirow[b]{2}{*}{0.003} \\
\hline $3+$ & 83 & $48.5 \%$ & 88 & $51.5 \%$ & & \\
\hline \multicolumn{6}{|l|}{ Spacing between pregnancies (Years) } & \\
\hline$<1$ & 38 & $33.0 \%$ & 77 & $67.0 \%$ & \multirow{4}{*}{10.629} & \multirow{4}{*}{0.014} \\
\hline $1-$ & 10 & $66.7 \%$ & 5 & $33.3 \%$ & & \\
\hline $2-$ & 67 & $46.9 \%$ & 76 & $53.1 \%$ & & \\
\hline $3+$ & 30 & 34.5 & 57 & $65.5 \%$ & & \\
\hline
\end{tabular}

Regarding the relationship between current pregnancy order and anemia, the highest prevalence of anemia $(48.5 \%)$ was among pregnant women whose pregnancy was the third and more. $(\mathrm{cOR}=0.518(0$ $\left..338,0.793), \mathrm{x}^{2} \mathrm{MH}=8.573, \mathrm{p}=0.003\right)$. The prevalence of anemia decreased with the increase in the interval between pregnancies: The highest prevalence of anemia was among pregnant women who have had spacing between pregnancies one year and below $\left(X^{2}=10.629, \mathrm{p}=0.014\right.$. $)$.

Logistic regression analysis shows that pregnant women how ate liver weekly, those who drank milk one to six days per week and those who were in the third and second trimesters of pregnancy had a significant impact on occurrence of anemia than the relevant categories (Table 3).

Table 3. Logistic Regression Analysis of Anemia Among Pregnant Women

\begin{tabular}{lccccc}
\hline \multicolumn{1}{c}{ Variable } & \multirow{2}{*}{$\mathrm{B}$} & Sig. & \multirow{2}{*}{ Exp(B) } & \multicolumn{2}{c}{ 95\% C.I.for EXP(B) } \\
Lower & .864 & Upper \\
\hline Interval between pregnancies & & .104 & .416 & 1.109 & 1.424 \\
Liver eating & 1.080 & .009 & 2.945 & .304 & 6.650 \\
Milk drinking & $-1.260-$ & .000 & .284 & .168 & .478 \\
Time of drinking tea & .106 & .690 & 1.112 & .659 & 1.876 \\
Current pregnancy & $-.549-$ & .060 & .578 & .326 & 1.023 \\
Time of cola drinking & $-.628-$ & .157 & .533 & .223 & 1.275 \\
Time of coffee drinking & .310 & .480 & 1.364 & .577 & 3.223 \\
Current pregnancy trimester & $-.673-$ & .000 & .510 & .371 & .702 \\
Constant & 4.361 & .000 & 78.363 & & \\
\hline
\end{tabular}

Regarding the knowledge of pregnant women about anemia, it appears from Figure 2 that the prevalence of anemia among pregnant women was highest among those who had poor level of knowledge constituted (63.2\%) compared to those who had good and fair level of knowledge (Figure 2). 


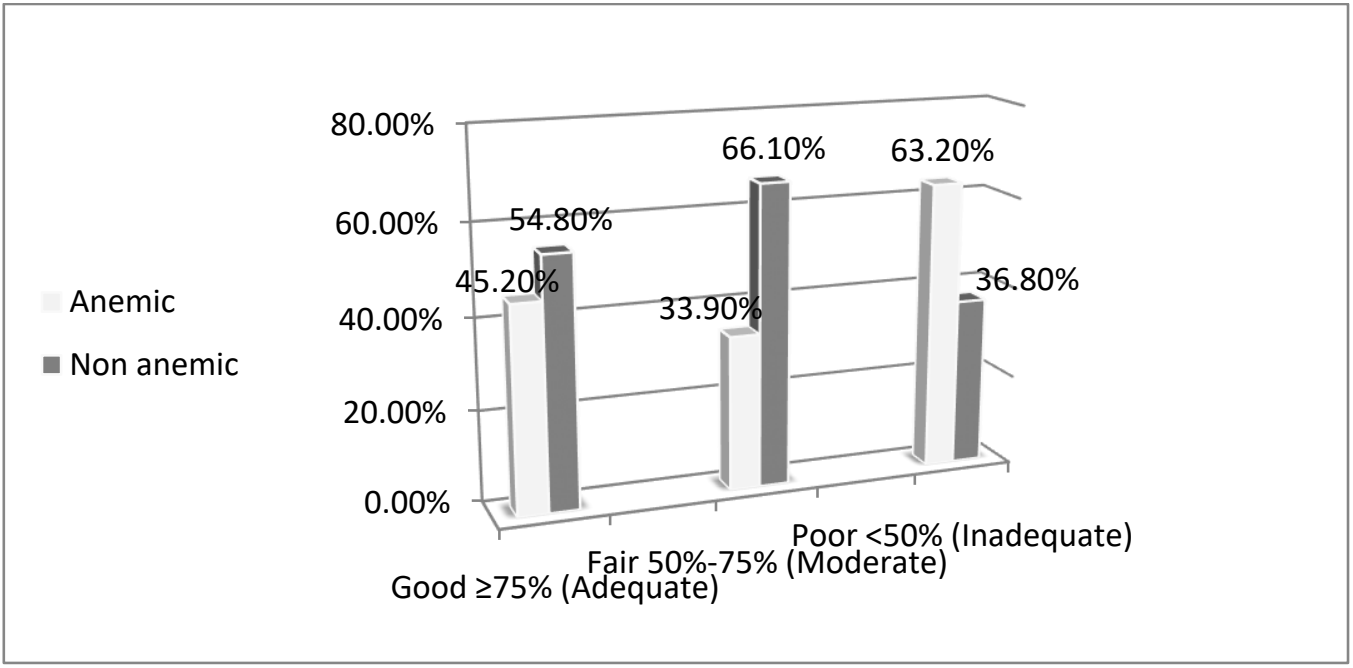

Figure 2. Relationship between level of knowledge and anemia

The difference was statistically significant $(\mathrm{p}=0.012)$. Logistic regression analysis of the factors affecting knowledge showed that the literate and working pregnant women had a significant good knowledge score than the relevant categories (Table 4).

Table 4. Logistic Regression Analysis of the Factors Affecting Knowledge Among Pregnant Women (Sana'a, Yemen)

\begin{tabular}{|c|c|c|c|c|c|}
\hline \multirow{2}{*}{ Variable } & \multirow{2}{*}{ B } & \multirow{2}{*}{ Sig. } & \multirow{2}{*}{$\operatorname{Exp}(B)$} & \multicolumn{2}{|c|}{$95 \%$ C.I.for $\mathrm{EXP}(\mathrm{B})$} \\
\hline & & & & Lower & Upper \\
\hline Age & .287 & .285 & 1.332 & .788 & 2.251 \\
\hline Education & 1.645 & $.000 *$ & 5.181 & 2.339 & 11.477 \\
\hline Income & $-.264-$ & .346 & .768 & .443 & 1.330 \\
\hline Occupation & $-.219-$ & $.010^{*}$ & .803 & .680 & .948 \\
\hline Residence & $-.545-$ & .141 & .580 & .281 & 1.198 \\
\hline Constant & $-1.450-$ & .166 & .234 & & \\
\hline
\end{tabular}

Accuracy of the model was $64.4 \%$

*Significant $(\mathrm{p}<0.05)$

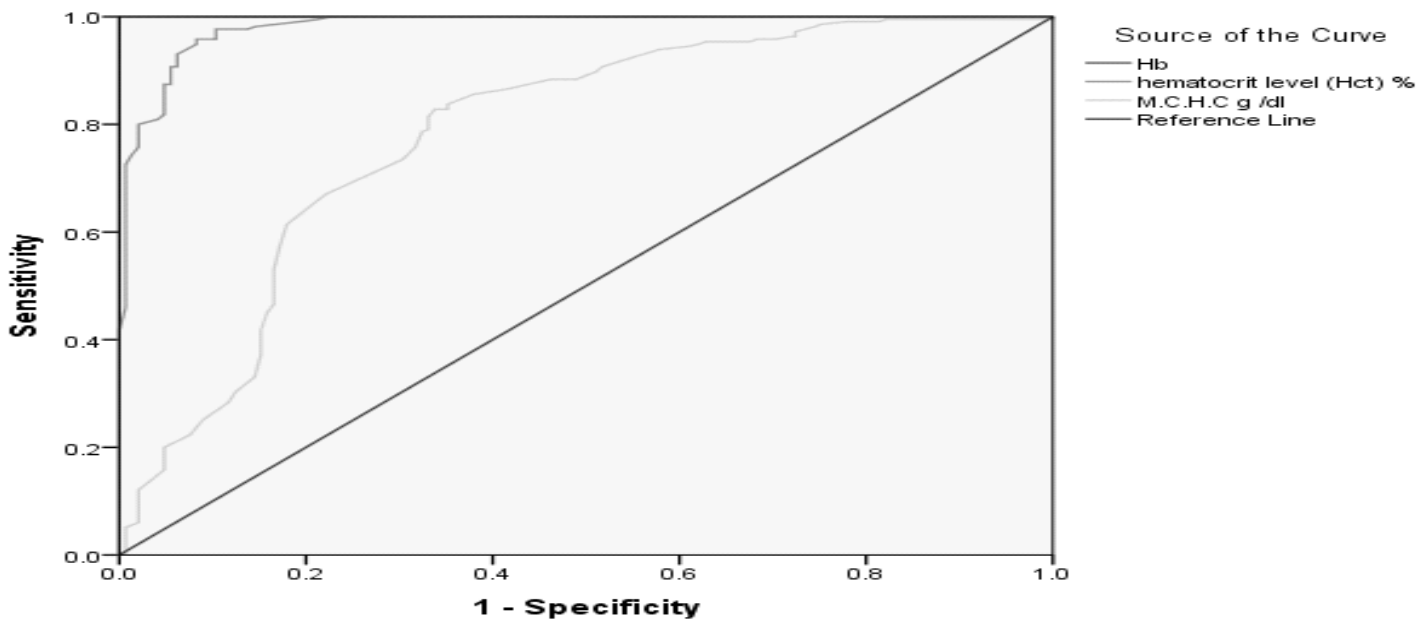

Figure 3. ROC curve analysis of probability of no anemia calculated from binary logistic model 
Figures 3 shows that the Area under the ROC curve (AUC) of $\mathrm{Hb}$ as a predictor of anemia among pregnant women in Sana'a governorate in Yemen. The area under the ROC curve was significantly different from 0.5 (null hypothesis area) and that therefore there is evidence that $\mathrm{Hb}$ has an ability to distinguish between the two positive and negative groups ( $\mathrm{P}$ (Area=0.5 was $<0.000)$.

\section{DISCUSSION}

The overall prevalence of anemia in the present study was $40.3 \%$ among pregnant women attending maternal outpatient clinics of the selected hospitals. This prevalence is consistent with the global study results (41.8\% and 38\%) reported from WHO in 2008 [1] and 2014 [4] respectively. Also, the prevalence estimated in the current study is in accordance with findings of a survey conducted in Yemen by the World Bank in 2011 which found that $36 \%$ of pregnant women were anemic [14]. Other studies done in 2011 by the World Bank estimated the prevalence of anemia among pregnant women to be $40 \%$ in Saudi Arabia, $38 \%$ in Bolivia, 39\% in Maldives and 44\% in Afghanistan [14]. Many studies done in different countries around the world showed that the prevalence of anemia was 41.4\% in Jordan (2012) [15] 41.6\% in Turkey (2015) [16] and $39.9 \%$ in Southern Ethiopia (2015) [17].

The prevalence of anemia in the current study is lower than that reported in the WHO global database on anemia between 1993 and 2005 in Yemen which was 58.1\% among pregnant women [1]. This might be attributed to improvement of health care services and socioeconomic state. It is lower than findings of some developing countries which were reported by the World Bank in 2011, (Nigeria 58\%, India 54\% and Pakistan 51\%) [14]. The prevalence of anemia in the current study was higher than that reported by the World Bank in 2011, in gulf and Arabian countries. It was 25\% in Kuwait, 26\% in United Arab Emirates, $27 \%$ in Lebanon, 27\% in Jordan, 28\% in Qatar, 31\% in Iraq, 34\% in Oman and 30\% in Egypt [14]. It is much higher than some developed countries as reported by the World Bank in 2011, such as 17\% in United States, $23 \%$ in United Kingdom and 27\% in Japan [14].

Anemia in pregnancy is related to different socio-demographic and behavioral factors [17]. The causes of anemia are multi-factorial, including gestational factors and diet, infection and genetics [14]. The current study revealed an association between prevalence of anemia and many factors as gestational age, gravidity, child spacing, milk drinking, time of tea drinking, time of coffee drinking, time of cola drinking, chicken eating, liver eating and level of knowledge. The relative contribution of each factor to anemia during pregnancy varies greatly by geographical location, season, and dietary practice [18]. In the current study, the prevalence of anemia increased with the decrease in the level of income. The highest prevalence of anemia (49.9\%) was among pregnant women who had poor income. Studies conducted in Turkey (2010 and 2015) [9],[16], Azad Kashmir, Pakistan (2012) [19], Ethiopia (2013 and 2016) [20],[21], were consistent with the current study and found a statistically significant association between the level of income and anemia in pregnancy.

In the present study, the risk of developing anemia increased with the advance in pregnancy. The risk of developing anemia among pregnant females was higher in third and second trimester when compared with those in the first trimester. This finding is consistent with the study conducted among pregnant females attending the primary health care centers in Makkah, Saudi Arabia (2012) [22], Additionally, studies conducted in Turkey (2010 and 2015) [9],[16], Pakistan (2013) [23], Ethiopia (2015) [17], found that the increase in gestational age is significantly associated with the risk of developing anemia. This could be due to the fact that when the gestational age increases the mother becomes weak and the iron in the blood is shared with the fetus in the womb therefore decreasing the iron binding capacity of the mother's blood [18].

In the present study, multigravidity was significantly associated with anemia $(p=0.003)$. The risk of developing anemia in pregnant women who had three and more pregnancies is increased when compared with those who had less than 3 pregnancies. This finding is consistent with studies conducted in Saudi Arabia (2012) [22] and Eastern Ethiopia (2014) [18]. This could be attributed to loss of iron and other nutrients as result of repeated pregnancies [18]. Higher gravidity was documented in a number of studies as a cause of anemia in pregnancy, as studies done in Jordan (2012) [15], Malaysia (2012) [24], Pakistan (2013) [23] and Ethiopia (2015) [17]. This is because of reducing maternal iron reserves at every pregnancy and blood loss at each delivery [22].

Child spacing was also found to be significantly associated with the occurrence of anemia in the current study ( $\mathrm{p}=0.014)$. Other studies done in Saudi Arabia (2012) [22], and Ethiopia (2012) [25], revealed similar findings. It could be noticed that the prevalence of anemia decreased with the increase in spacing between pregnancies. These findings are consistent with the results of the current study and could be explained by the fact that short intervals between births may not provide women with enough time to replenish lost nutrient stores before another reproductive cycle begins. Another explanation is that child spacing minimizes bleeding during delivery and enhances iron reserve in the body [25]. Results of the 
present study showed that awareness had a very significant effect on the occurrence of anemia among pregnant women. Anemic pregnant women who had poor level of knowledge constituted 63.2\%. The prevalence of anemia among pregnant women increased with the decrease in knowledge level. This finding is consistent with study done in Sudan (2014) [26].

In the current study, logistic regression analysis of the factors affecting knowledge showed that education and occupation (literacy and work) were significantly associated with knowledge of the pregnant women. This finding is consistent with findings of previous studies done in India (2014) [27]. Results of the present study showed that the area under the ROC curve of $\mathrm{Hb}$ as a predictor of anemia among pregnant women was the highest of all various red cell indices. Other studies were in agreement and found that the $\mathrm{ROC}$ for $\mathrm{Hb}$ give the maximum area under its curve and can predict iron deficiency anemia in the second and third trimester with a high sensitivity and specificity [28],[29].

\section{CONCLUSION}

Anemia is a global public health problem affecting both developing and developed countries with major consequences for human health as well as social and economic development. Anemia was found out to be a severe public health problem in Yemen. Identified risk factors should be considered for prevention and control of anemia among pregnant women.

\section{ACKNOWLEDGEMENTS}

The authors would like to thank all the study participants for their cooperation.

\section{REFERENCES}

[1] World Health Organization, "Worldwide prevalence of anemia 1993-2005. WHO global database on anemia," Geneva, WHO, pp. 40, 2008.

[2] World Health Organization, "Worldwide prevalence of anemia, WHO Vitamin and Mineral Nutrition Information System, 1993-2005," Geneva, WHO, pp. 11, 2008.

[3] Centers for Disease Control and Prevention, "Indicators and methods for cross-sectional surveys of vitamin and mineral status of populations," Atlanta, CDC, pp. 152, 2007.

[4] World Health Organization, "Global targets 2025. Anemia policy brief," Geneva, WHO, pp. 7, 2014.

[5] World Health Organization, "Guideline: Daily iron and folic acid supplementation in pregnant women," Geneva, WHO, pp. 27, 2012.

[6] Kalaivani K., "Prevalence and consequences of anemia in pregnancy," Indian J Med Res., vol. 130, pp. 627-33, 2009.

[7] World Health Organization, "Iron deficiency anemia: assessment, prevention, and control. A guide for programme managers," Geneva, WHO, pp. 114, 2001.

[8] Charles C. V., "Public Health - Methodology, environmental and systems issues. Iron deficiency anemia: A public health problem of global proportions," InTech, pp. 432, 2012.

[9] Karaoglu L., et al., "The prevalence of nutritional anemia in pregnancy in an east Anatolian province, Turkey," BMC Public Health, vol. 10, pp. 329, 2010.

[10] Oliver E. and Olufunto K., “Anemia. Management of anemia in pregnancy,” Nigeria, InTech, pp. 246, 2012.

[11] World Health Organization, "Standards for Maternal and Neonatal Care. Integrated Management of Pregnancy and Childbirth. Iron and folate supplementation," Geneva, WHO, pp. 6, 2006.

[12] P. Rosas J. P. and Viteri F. E., "Effects and safety of preventive oral iron or iron and folic acid supplementation for women during pregnancy (Review). The Cochrane Collaboration,” John Wiley \& Sons Ltd, vol. 4, pp. 239, 2009.

[13] World Health Organization, "Guideline: Preventing and controlling iron deficiency anemia through primary health care," Geneva, WHO, pp. 58, 1989.

[14] The World Bank, "Prevalence of anemia among pregnant women. World development indicators," Washington, World Bank, pp. 6, 2015.

[15] Mohammad A. and Salahat I., "Prevalence of anemia among Jordanian pregnant women and the effect of early pregnancy on Alkaline phosphatase activity," JJBS, vol/issue: 5(1), pp. 65-70, 2012.

[16] Taner C. E., et al., "Prevalence and risk factors of anemia among pregnant women attending a high-volume tertiary care center for delivery," J Turk Ger Gynecol Assoc, vol. 16, pp. 231-6, 2015.

[17] Gedefaw L., et al., "Anemia and associated factors among pregnant women attending antenatal care clinic in Wolayita Sodo Town, Southern Ethiopia,” Ethiop J Health Sci., vol/issue: 25(2), pp. 155-62, 2015.

[18] Alene K. A. and Dohe A. M., "Prevalence of anemia and associated factors among pregnant women in an urban area of Eastern Ethiopia," J of Hindawi, vol/issue: 10(1155), pp. 1-7, 2014.

[19] Abbasi A., et al., "Causes of anemia in pregnant women of the State of Azad Kashmir: A cross-sectional survey," $J$ of Health. Sci Res., vol. 5, pp. 35-44, 2014. 
[20] Alem M., et al., "Prevalence of anemia and associated risk factors among pregnant women attending antenatal care in Azezo Health Center Gondar town, Northwest Ethiopia," J Interdiscipl Histopathol, vol/issue: 1(3), pp. 137-44, 2013.

[21] Bekele A., et al., "Prevalence of anemia and its associated factors among pregnant women attending antenatal care in health institutions of Arba Minch Town, Gamo Gofa Zone, Ethiopia: A Cross-Sectional Study," J of Hindawi, vol/issue: 10(1155), pp. 1-9, 2016.

[22] Abdelhafez A. M. and E. Soadaa S. S., "Prevalence and risk factors of anemia among a sample of pregnant females attending primary health care centers in Makkah, Saudi Arabia," Pakistan J Nut., vol/issue: 11(12), pp. 1113-20, 2012.

[23] Naz H. and Begum B., "Prevalence and associated risk factors of anemia in pregnant women in a teaching hospital, Korangi Industrial Area," Pak J Surg, vol/issue: 29(2), pp. 131-3, 2013.

[24] Rosmawati N. H., et al., "The rate and risk factors for anemia among pregnant mothers in Jerteh Terengganu, Malaysia," J Community Med Health Educ., vol/issue: 2(5), pp. 1-4, 2012.

[25] Obse N., et al., "Magnitude of anemia and associated risk factors among pregnant women attending antenatal care in Shalla Woreda, West Arsi Zone, Oromia Region, Ethiopia," Ethiop J Health Sci., vol/issue: 23(2), pp. 165-73, 2013.

[26] Morsy N. and Alhady S., "Nutritional status and socio-economic conditions influencing prevalence of anemia in pregnant women," IJSTR, vol/issue: 3(7), pp. 54-60, 2014.

[27] Yadav R. K., et al., "Knowledge and practice of anemia among pregnant women attending antenatal clinic in Dr. Prabhakar Kore Hospital, Karnataka," JDMS, vol/issue: 13(4), pp. 74-80, 2014.

[28] Tiwari L. M., et al., "Correlation of hemoglobin and red cell indices with serum ferritin in Indian women in second and third trimester of Pregnancy," Medical Journal Armed Forces India, vol. 69, pp. 31-6, 2013.

[29] Casanova B. F., et al., "Development of a clinical prediction rule for iron deficiency anemia in pregnancy," American Journal of Obstetrics and Gynecology, vol/issue: 193(2), pp. 460-6, 2005. 